\title{
Somogy megye pókfaunája (Aranea)
}

\author{
SZINETÁR CSABA
}

SZINETÁR Cs.: Spider fauna of Somogy county (Aranea)

Abstract: CHYZER and KULCZYNSKI (1891, 1894, 1897), KOLOSVÁRY (1935), LOKSA (1975, 1980, 1985, in SZINETÁr 1998), FARKAS et al (1998), as well as the author (SZINETÁr 1992, 1998) participated in the researches on spider fauna of Somogy county. As a result of these investigations, 334 spider species were identified in the area of Somogy county. This means $46 \%$ of the Hungarian spider fauna (SAMU \& SZINETÁr 1999).

\section{Bevezetés}

A Somogy megye területére vonatkozó első pókfaunisztikai adatokat CHYZER és KulCZYNSKi (1891, 1894, 1897) múvében találjuk. Több lelkes gyứjtő (Bíró Lajos, Jablonovszky József, Horváth Géza, Lendl Adolf, Pável János) közremúködésének köszönhetôen elsősorban a Balaton déli partvidékéról (Balatonföldvár, Balatonszentgyörgy, Boglár, Fonyód, Lelle, Szántód), valamint Szulok, és Zákány településekról rendelkezünk adatokkal. A fenti adatok az alábbiakban szereplő faunalistában a település nevével, valamint az Araneae Hungariae II. kötetének megjelenési évszámával (1897) szerepelnek. A korábbi kutatások tekintetében megemlítendő még Kolosváry Gábornak a hazai borókások állatvilágára vonatkozó közleménye. A szerző cikkében utalt a darányi borókásra, ahol több állatcsoporttal együtt a borókán élô pókokat is vizsgálta (Kolosváry 1935). A Barcsi Borókás TK területének faunisztikai feltárásában jelentôs szerepe volt Loksa Imrének is, aki több állatcsoporttal együtt a pókokat is begyújtötte. Az általa gyújtött, és részben feldolgozott anyag publikálása a Duna-Dráva Nemzeti Park kutatásának II. kötetében történt meg (SzINETÁr 1998). Loksa Imre gyújtéseinél (1975, 1980, 1985) lelőhelyként egységesen az általa is használt „Barcs“ lelóhelyi hivatkozás szerepel. A megye területének pókfaunisztikai feltárásába e közlemény szerzóje a kilencvenes évek elején kapcsolódott be a Somogy Megyei Múzeum felkérésére. A Boronka-melléki Tájvédelmi Körzet kutatása a megye középső területének tipikus élóhelyeirôl, néhány más ízeltlábú taxonhoz hasonlóan, a pókokról is tekintélyes mennyiségú adatot eredményezett. Különösen értékesnek bizonyultak a jó természetességú állapotú savanyú homoki gyepek és égeres láperdôk (SzINETÁr 1992). Ezen vizsgálatok során fontosabb lelóhelyekként Böhönye (Mernyei-erdó), Nagybajom (Farakodó), Gyótapuszta (Gyótai-erdő), és Hosszúvíz említendók. A kilencvenes évek második felében a Duna-Dráva Nemzeti Park kutatása keretében a Janus Pannonius Múzeum irányításával a nemzeti park Somogy megye területéhez tartozó részein is folytak vizsgálatok, így a Zákány-Ôrtilosi dombokon, a Barcsi Borókás Tájvédelmi Körzetben, valamint Bélavár, Bolhó, Babócsa, Potony és Tótújfalu körzetében. Farkas János 
és munkatársai 1993-94-ben Siófok közelében, a Töreki-halastavak körzetében végeztek gyüjtéseket. A kimutatott pókok, ugróvillások, valamint bogarak adatait egy publikációban közölték (FARKAS és mtsi. 1998).

A hazai pókfauna irodalmi adatokon alapuló faunalistája 1999-ben készült el (SAMU \& SZINETÁR 1999). Ennek alapján Magyarország mai határain belül 725 pókfajról rendelkezünk adattal. A Somogy megye területéról eddig ismertté vált 334 pókfaj a hazai fauna 46\%-a. Tekintettel arra, hogy a megye nagy része mindmáig feltáratlannak tekinthetố, ez a szám még jelentôsen emelkedhet. Különösen érdekes lehet a késóbbiekben a Zselic, valamint a Balaton somogyi partvidékének a kutatása. Remélhetôleg jelen közlemény is hozzájárul Somogy megye természeti értékeinek megismertetéséhez, és a későbbi kutatásokra is inspirálólag hat.

\section{Somogy megye területérôl kimutatott pókfajok listája}

- A fajlistában a lelóhelyek, valamint a publikálás, illetve egyes esetekben a gyújités évszáma szerepel. A gyứjtớk nevét a késôbbiekben külön nem tüntetjük fel. A gyújtók személye a lelôhelyek, valamint évszámok alapján az alábbiak szerint visszakereshetö:

- Balatonboglár, Balatonföldvár, Balatonszentgyörgy, Fonyód, Lelle, Szántód, Szulok, Zákány települések 1897-es évszámmal megadott adatai Bíró Lajos, Chyzer Kornél, Jablonovszky József, Horváth Géza, Lendl Adolf, Pável János gyújtóktöl származnak. (CHYZER és KULCZYNSKi I 891, 1894, 1897).

- Barcs 1975, 1980 és 1985-ös adatai Loksa Imre gyújtései (SzINETÁr 1998)

Töreki 1994-as adatai Farkas János és munkatársainak a Töreki-halastavaknál végzett gyüjtései.

- 1992-2000-es évszámú gyújtések Szinetár Csaba, valamint a Somogy, illetve Baranya Megyei Múzeumok Természettudományi Osztályai munkatárasainak gyúitései. A Dolomedes plantarius (Vízvár 1999) adata Kovács Tibor (Mátra Múzeum) gyúitése.

Torzpókfélék - Atypidae

Atypus affinis Eichwald, 1830 - Barcs 1975.

Atypus piceus (Sulzer, 1776) - Gyótapuszta

1992., Nagybajom 1992., Töreki 1994.

Aknászpólffélék - Nemesiidae

Nemesia pannonica (Herman, 1879) Barcs 1975.

Álkaszáspókok - Pholcidae

Pholcus opilionoides (Schrank, 1781) -

Örtilos 1996.

\section{Darócpókok - Segestridae}

Segestria bavarica C.L. Koch, 1843 - Órtilos 1996.

Segestria senoculata (Linnaeus, 1758) Böhönye 1992.
Folytópókok - Dysderidae

Dysdera crocota C.L. Koch, 1838 Böhönye 1992.

Dysdera longirostris Doblika, 1853 - Bolhó 1993., Böhönye 1992.

Dysdera ninnii Canestrini, 1868 - Órtilos 1993.

Harpactea rubicunda (C.L. Koch, 1838) Töreki 1994.

\section{Bütykös pókok - Mimetidae}

Ero aphana (Walckenaer, 1802) - Barcs

1975., Darány 1997., Örtilos 1996., 1997.

Ero furcata (Villers, 1789) - Barcs 1975., Böhönye 1992., Gyótapuszta 1992., Örtilos 1996. Ero tuberculata (Degeer, 1778) - Barcs 1985., Órtilos 1992. 


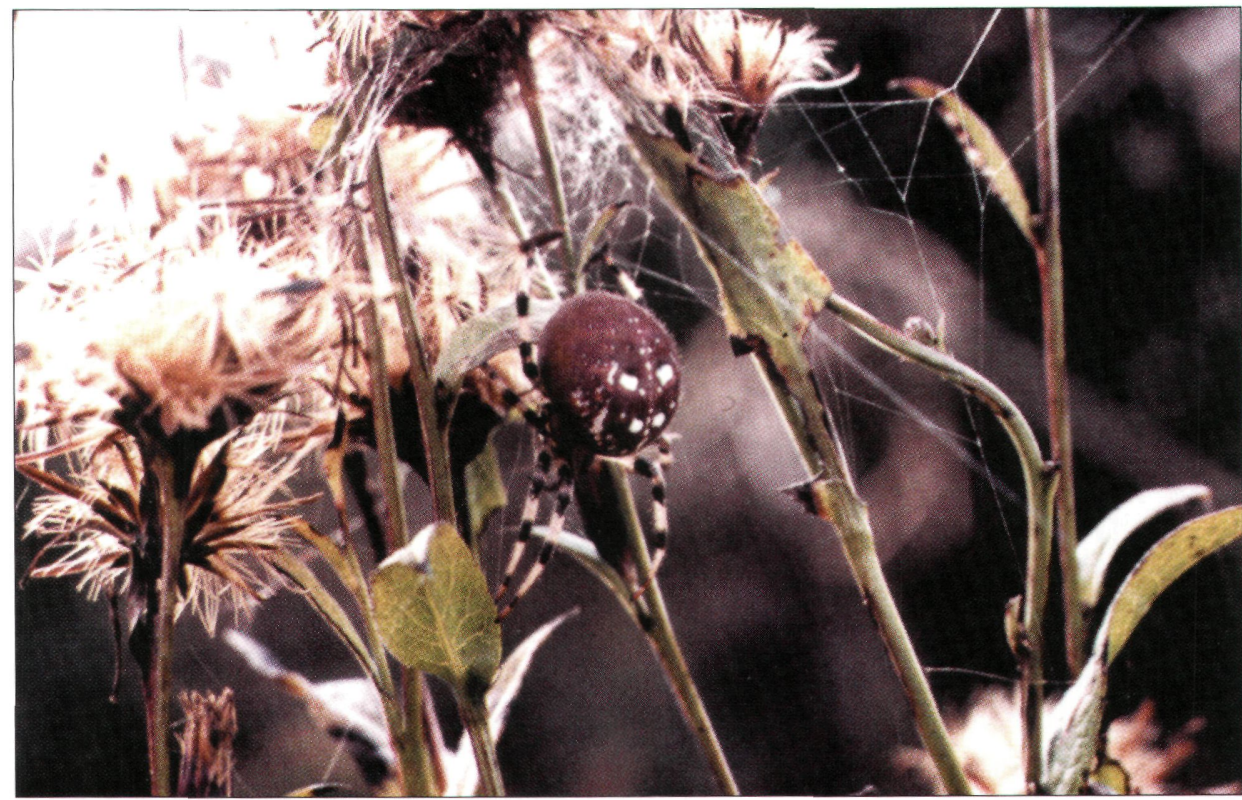

1. ábra: Négyes keresztespók (Araneus quadratus) Fotó: Szinetár Cs.

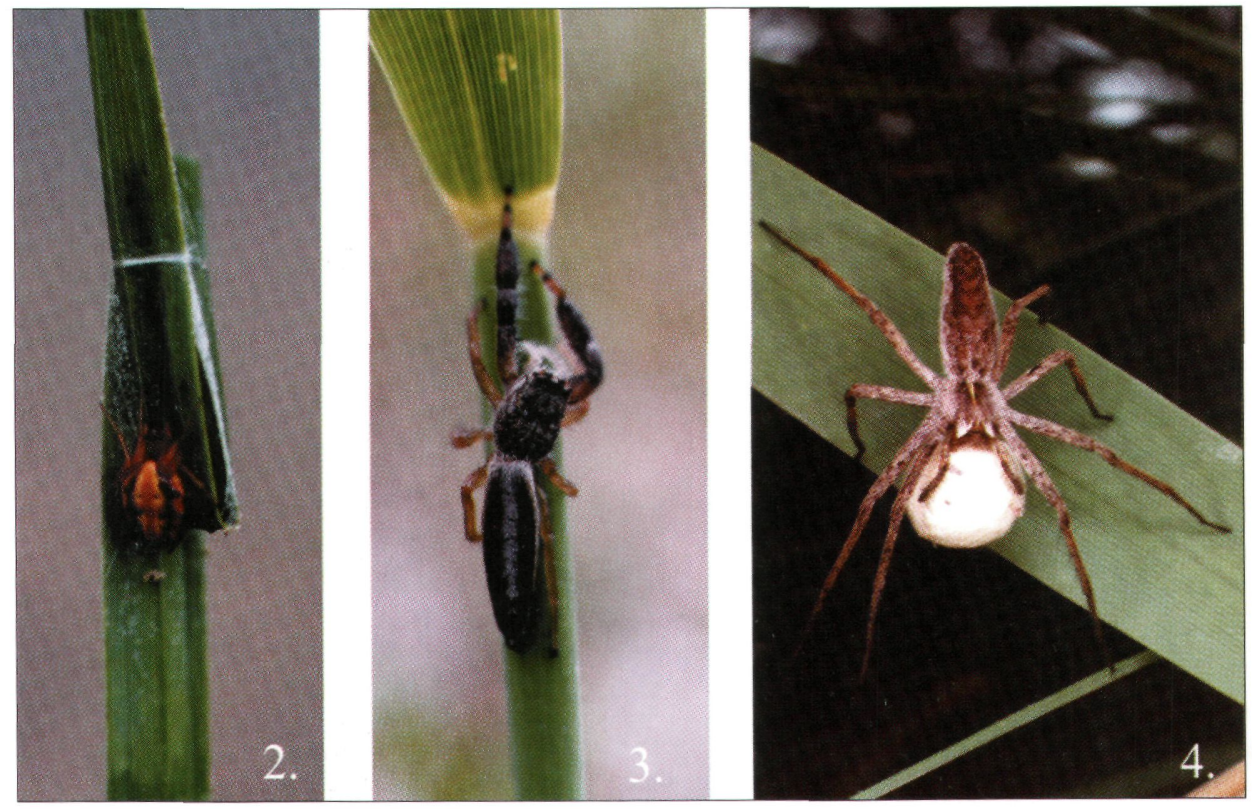

2. ábra: Csipkés keresztespók (Hypsosinga heri) Fotó: Szinetár Cs. 3. ábra: Nádi ugrópók (Marpissa canestrinii) Fotó: Szinetár Cs. 4. ábra: Csodáspók (Pisaura mirabilis) Fotó: Szinetár Cs. 


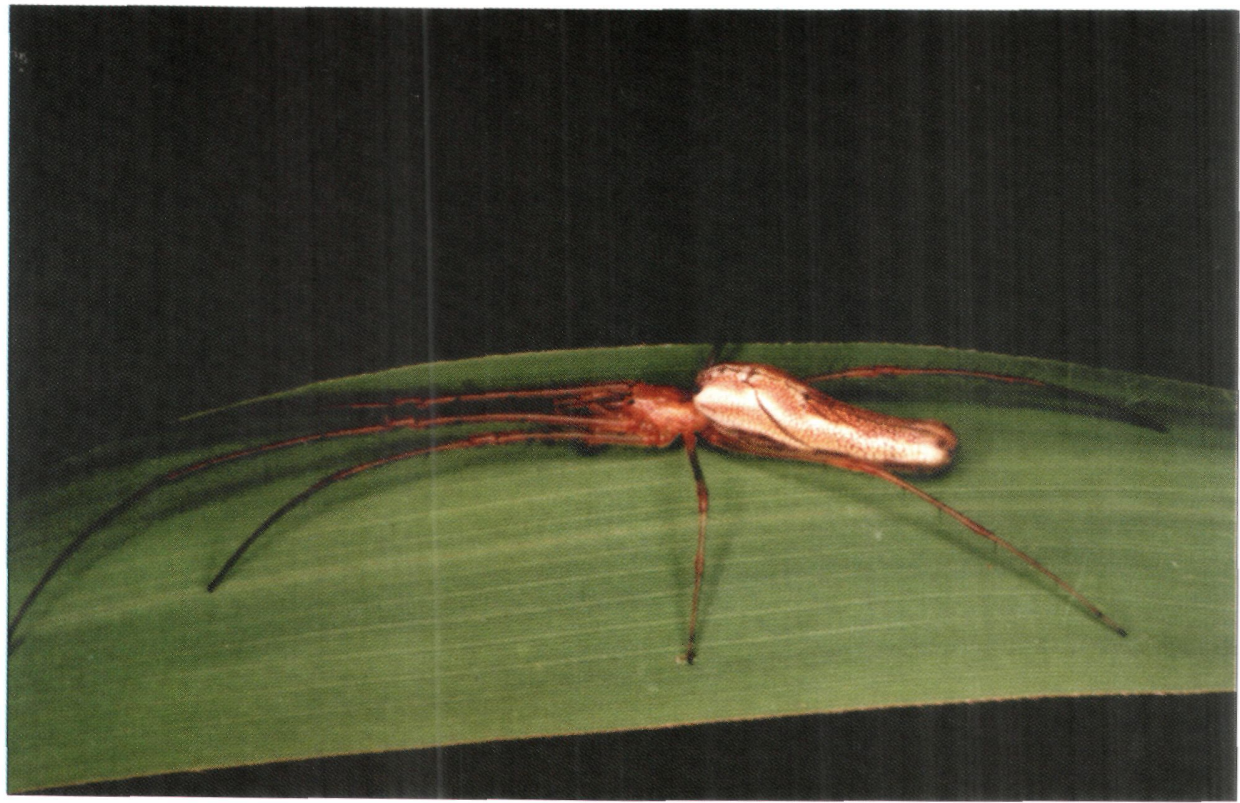

5. ábra: Hegyi állaspók (Tetragnatha montana) Fotó: Szinetár Cs.

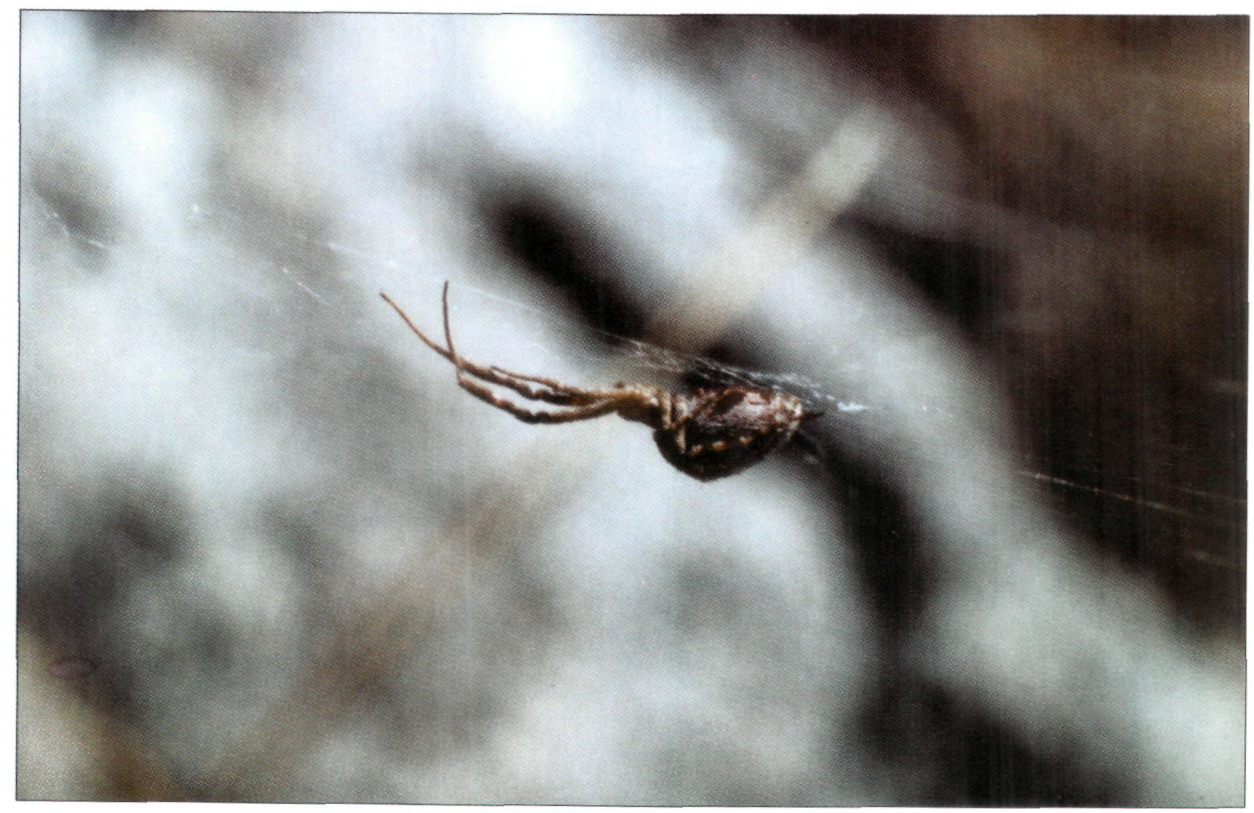

6. ábra: Derespók (Uloborus walckenarius) Fotó: Szinetár Cs. 


\section{Derespókok - Uloboridae} Hyptiotes paradoxus (C.L. Koch, 1834) Gyékényes 1994.

Uloborus walckenaerius (Latreille, 1806) Darány 1992., 1994.,1997., Nagybajom 1992.

\section{Törpepókok - Theridiidae}

Achaearanea lunata (Clerck, 1757) -

Böhönye 1992., Örtilos 1992.

Achacuranea simulans (Thorell, 1875) -

Örtilos 1995.

Achaearanea tepidariorum (C.L. Koch, 1841) -

Babócsa 1997.

Crustulina guttata (Wider, 1834) - Barcs

1980., Hosszúvíz 1992.

Dipoena melanogaster (C.L. Koch, 1837) -

Böhönye 1992., Hosszúvíz 1992., Nagybajom 1992., Örtilos 1992.

Enoplognatha latimana Hippa \& Oksala, 1982 - Darány 1997.

Enoplognatha ovata (Clerck, 1757) -

Babócsa 1997., Barcs 1985., Böhönye 1992., Darány 1994., 1997., Hosszúvíz 1992., Nagybajom 1992., Órtilos 1995., 1996., Töreki 1994., Zákány 1897.

Enoplognatha thoracica (Hahn, 1833) ) -

Balatonboglár 1897.

Episinus angulatus (Blackwall, 1836) Barcs 1980., Töreki 1994.

. Episinus truncatus Latreille, 1809 - Darány

1997., Nagybajom 1992.

Euryopis flavomaculata (C.L. Koch, I836) -

Barcs 1975., Böhönye 1992., Nagybajom 1992., Töreki 1994.

Euryopis saukea Levi, 1951 - Darány 1994., 1997.

Lasaeola tristis (Hahn, 1833) - Barcs 1985.

Pholcomma gibbum (Westring, 1851) -

Hosszúvíz 1992.

Robertus lividus (Blackwall, 1836) - Barcs 1975., Örtilos 1996.

Rugathodes instabile O.P.- Cambridge, 1871 Gyékényes 1995.

Steatoda castanea (Clerck, 1757) Balatonboglár 1897.

Steatoda phalerata (Panzer, 1801) - Nagybajom 1992., Töreki 1994.

Theridion bimaculatum (Linnaeus, 1767) Bélavár 1996., Gyótapuszta 1992., Nagybajom 1992.

Theridion hemerobius Simon, 1914 - Órtilos 1995.

Theridion impressum L. Koch, 1881 Bélavár 1996., Tótújfalu 1994.

Theridion melanurum Hahn, 1831 - Darány 1997., Szántód 1897.
Theridion pictum (Walckenaer, 1802) Órtilos 1995., 1996., 1997., Nagybajom 1992.

Theridion tinctum (Walckenaer, 1802) Bélavár 1994., Böhönye 1992., Nagybajom 1992.,Órtilos 1992., Potony 1994.

Theridion varians Hahn, 1833 - Böhönye 1992., Gyótapuszta 1992., Hosszúvíz 1992., Nagybajom 1992., Ôrtilos 1995., Potony 1994.

Törpe-keresztespókok - Theridiosomatidae Theridiosoma gemmosum (L. Koch, 1877) Ôrtilos 1996., 1997.

\section{Paránypókok - Mysmenidae}

Mysmenella jobi (Kraus, 1967) - Barcs 1985., Örtilos 1996., 1997.

\section{Vitorláspókok - Linyphiidae}

Abacoproeces saltuum (L. Koch, 1872) -

Böhönye 1992., Gyótapuszta 1992.

Araeoncus humilis (Blackwall, 1841) -

Barcs 1975., Bélavár 1996., Darány 1997.

Bathyphantes gracilis (Blackwall, 1841) Örtilos 1996.

Bathyphantes nigrinus (Westring, 1851) Barcs 1985., Bélavár 1996., Hosszúvíz 1992., Nagybajom 1992., Órtilos 1996.

Bathyphantes similis Kulczynski, 1894 Örtilos 1996.

Centromerus sylvaticus (Blackwall, 1841) Barcs 1975., Böhönye 1992., Órtilos 1996.

Ceratinella major Kulczynski, 1894 - Barcs 1980.

Ceratinella scabrosa (O.P.-Cambridge, 1871) Barcs 1980.

Diplostyla concolor (Wider, 1834) - Barcs 1980., Gyótapuszta 1992., Hosszúvíz 1992., Nagybajom 1992., Őrtilos 1996., 1997., Töreki 1994.

Drapetisca socialis (Sundevall, 1833) Barcs 1985.

Entelecara acuminata (Wider, 1834) - Örtilos 1996. 1996.

Erigone dentipalpis (Wider, 1834) - Bélavár

Floronia bucculenta (Clerck, 1757) Bélavár 1994., 1996.

Frontinellina frutetorum (C.L. Koch, 1834) Darány 1997., Szántód 1897.

Gnathonarium dentatum (Wider, 1834) Barcs 1975., Örtilos 1995., 1996., 1997.

Gongylidiellum murcidum Simon, 1884 Barcs 1980., Örtilos 1995., 1996.

Gongylidium rufipes (Linnaeus, 1758) Böhönye 1992., Hosszúvíz 1992., Nagybajom 1992., Örtilos 1995., Zákány 1897. 
Hylyphantes nigritus (Simon, 1881) Nagybajom 1992.

Hypomma bituberculatum (Wider, 1834) Gyótapuszta 1992., Órtilos 1996.

Hypomma cornutum (Blackwall, 1833) -

Nagybajom 1992.

Lepthyphantes angulipalpis (Westring, 1851) Barcs 1975.

Lepthyphantes flavipes (Blackwall, 1854) -

Barcs 1975., Böhönye 1992.

Lepthyphantes mengei Kulczynski, 1887 —

Barcs 1975.

Lepthyphantes minutus (Blackwall, 1833) -

Bélavár 1994.

Lepthyphantes pallidus (O.P.-Cambridge,

1871) - Barcs 1975., Böhönye 1992.

Lepthyphantes tenebricola (Wider, 1834) -

Barcs 1980., Böhönye 1992., Gyótapuszta 1992., Hosszúvíz 1992.

Linyphia hortensis Sundevall, $1830-$

Böhönye 1992., Gyótapuszta 1992.,

Hosszúvíz.1992., Nagybajom 1992.

Linyphia triangularis (Clerck, 1757) - Barcs

1985., Bélavár 1994., Böhönye 1992., Gyéké-

nyes 1994., Gyótapuszta. 1992., Hosszúvíz

1992., Nagybajom., Órtilos 1992., 1996.,

Porrogszentkirály 1994., Potony 1994.,

Tótújfalu 1994., Töreki 1994.

Macrargus rufus (Wider, 1834) - Böhönye 1992.

Maso sundevalli (Westring, 1851) - Barcs 1985.

Meioneta fuscipalpis (C.L. Koch, 1836) Barcs 1985.

Microlinyphia impigra (O.P.-Cambridge, 1871) - Barcs 1985.

Microneta viaria (Blackwall, 184I) - Barcs

1975., Gyótapuszta 1992.

Minicia marginella (Wider, 1834) - Barcs 1975.

Minyriolus pusillus (Wider, 1834) - Barcs 1985.

Nematogmus sanguinolentus (Walckenaer, 1841) - Örtilos 1996.

Neriene clathrata (Sundevall, 1830) - Barcs 1980., Böhönye 1992., Gyótapuszta 1992., Hosszúvíz 1992., Őrtilos 1993., 1996., 1997.

Neriene montana (Clerck, 1757) - Nagybajom 1992., Ôrtilos 1997.

Neriene peltata (Wider, 1834) - Böhönye 1992.

Neriene radiata (Walckenaer, 1841) - Barcs 1980., Gyótapuszta 1992.

Oedothorax apicatus (Blackwall, 1850) Bélavár 1996., Zákány 1897.

Oedothorax fuscus (Blackwall, 1834) Bélavár 1996.
Panamomops mengei Simon, 1926 - Barcs 1975., Örtilos 1996.

Pelecopsis elongata (Wider, 1834) - Barcs 1980.

Pelecopsis parallela (Wider, 1834) -

Gyótapuszta 1992.

Pocadicnemis pumila (Blackwall, 1841) -

Gyótapuszta 1992

Poeciloneta variegata (Blackwall, 1841) -

Barcs 1975.

Porrhomma microphthalmum (O.P.-Cambridge, 1871) - Bélavár 1994.

Saloca diceros (O.P.-Cambridge, 1871) Órtilos 1996.

Sintula spiniger (Balogh, 1935) - Barcs 1985.

Stemonyphantes lineatus (Linnaeus, 1758) Örtilos 1996. 1975.

Tapinocyba insecta (L. Koch, 1869) - Barcs

Trematocephalus cristatus (Wider, 1834) Hosszúvíz 1992., Nagybajom 1992.

Trichoncus hackmani Millidge, 1856 - Barcs 1975.

Walckenaeria antica (Wider, 1834) - Barcs 1975.

Walckenaeria atrotibialis (O.P.-Cambridge, 1878) - Hosszúvíz 1992.

Walckenaeria cucullata (C.L. Koch, 1836) Böhönye 1992.

Walckenaeria furcillata (Menge, 1869) -Barcs 1980., Böhönye 1992.

Walckenaeria melanocephala (O.P.-Cambridge, 1831) - Barcs 1975., Töreki 1994.

Walckenaeria nudipalpis (Westring, 1851) Böhönye 1992.

Walckenaeria obtusa Blackwall, 1836 Barcs 1975.

\section{Állaspókok - Tetragnathidae}

Metellina mengei (Blackwall, 1869) - Töreki 1994.

Metellina segmentata (Clerck, 1757) - Barcs 1985., Böhönye 1992., Gyótapuszta 1992., Hosszúvíz 1992., Nagybajom 1992., Ôrtilos 1992., 1996., 1997.

Pachygnatha clercki Sundevall, 1823 - Barcs 1985., Böhönye 1992., Nagybajom 1992., Órtilos 1992.

Pachygnatha degeeri Sundevall, 1830 Barcs 1975., Nagybajom 1992., Örtilos 1996.

Pachygnatha listeri Sundevall, 1830 - Barcs 1985., Bolhó 1993., Böhönye 1992., Gyótapuszta 1992., Hosszúvíz 1992., Nagybajom 1992., Örtilos 1996. 
Tetragnatha extensa (Linnaeus, 1758) Gyékényes 1994., Örtilos 1995., 1996., 1997.

Tetragnatha montana Simon, 1874 - Barcs 1997., Böhönye 1992., Hosszúvíz 1992., Nagybajom 1992., Örtilos 1995., 1996., 1997., Töreki 1994.

Tetragnatha nigrita LendI, I 886 - Örtilos 1995., 1996., 1997.

Tetragnatha obtusa C.L. Koch, 1837 Darány 1997. ki 1994

Tetragnatha pinicola L. Koch, 1870 - Töre-

Tetragnatha reimoseri (Rosca, 1939) - Örti$\operatorname{los} 2000$.

\section{Keresztespókok - Araneidae}

Aculepeira ceropegia (Walckenaer; 1802) Szulok 1897.

Agalenatea redii (Scopoli, 1763) - Darány 1994., Hosszúvíz 1992., Nagybajom 1992., Örtilos 1992.

Araneus alsine (Walckenaer, 1802) Bélavár 1994.

Araneus angulatus Clerck, 1757 - Bélavár 1994., Nagybajom 1992., Ốrtilos 1995., Potony 1994.

Araneus diadematus Clerck, 1757 - Barcs 1985., Darány 1997., Gyékényes 1995., Nagybajom 1992., Örtilos 1992., 1995., 1996. Porrogszentkirály 1994., Potony 1994., Tótújfalu 1994.

Araneus marmoreus Clerck, 1757 - Nagybajom 1992., Örtilos 1992., Töreki 1994.

Araneus quadratus Clerck, 1757 - Gyékényes 1995.,Hosszúvíz 1992., Nagybajom 1992., Órtilos 1992., 1994., Porrogszentkirály 1994.

Araneus triguttatus (Fabricius, 1775) Nagybajom 1992.

Araniella cucurbitina (Clerck, 1757) -

Darány 1997., Töreki 1994., Zákány 1897.

Araniella opistographa (Kulczynski, 1905) Böhönye 1992., Gyótapuszta 1992., Hosszúvíz 1992., Nagybajom 1992.,

Araniella displicata (Hentz, 1847) -

Darány 1997., Hosszúvíz 1992.

Argiope bruennichi (Scopoli, 1772) Bélavár 1996., Darány 1994., 1997., Nagybajom 1992., Órtilos 1996., 1997. Porrogszentkirály 1994.

Cercidia prominens (Westring, 1851) Barcs 1985., Gyótapuszta 1992., Nagybajom 1992., Örtilos 1997.

Cyclosa conica (Pallas, 1772) - Barcs 1985. Gyékényes 1994., Hosszúvíz 1992., Nagybajom 1992., Potony 1994.
Gibbaranea bituberculata (Walckenaer, 1802) - Böhönye 1992., Nagybajom 1992., Órtilos 1996

Hypsosinga albovittata (Westring, 1851) Darány 1994.

Hypsosinga heri (Hahn, 1831) - Barcs 1985., Hosszúvíz 1992., Órtilos 1995., 1996., 1997., Töreki 1994.

Hypsosinga pygmaea (Sundevall, 1832) Hosszúvíz 1992.

Larinioides cornutus (Clerck, 1757) sensu lato - Balatonboglár 1897.

Larinioides folium (Schrank, 1803) - Gyékényes 1994., Örtilos 1995., 1997.,

Larinioides patagiatus (Clerck, 1757) Ôrtilos 1992.

Larinioides sclopetarius (Clerck, 1757) Balatonboglár 1897.

Mangora acalypha (Walckenaer, 1802) Barcs 1985., Bélavár 1996., Darány 1997., Gyékényes 1994., Gyótapuszta 1992., Hosszúvíz 1992., Nagybajom 1992., Örtilos 1992., 1995., Szulok 1897., Töreki 1994.

Neoscona adianta (Walckenaer, 1802) Darány 1992., 1997., Hosszúvíz 1992., Nagybajom 1992.

Nuctenea umbratica (Clerck, 1757) Balatonboglár 1897., Bélavár 1994.

Singa hamata (Clerck, 1757) - Bélavár 1994., 1996., Gyékényes 1995., Hosszúvíz 1992., Örtilos 1992., 1996., Szulok 1897., Töreki 1994., Zákány 1897. 1897

Singa lucina Audouin, 1826 - Balatonlelle

Singa nitidula C.L. Koch, 1844 - Gyékényes 1994., Örtilos 1995., 1997., Töreki 1994., Zákány 1897.

Zilla diodia (Walckenaer, 1802) - Barcs 1985., Darány 1997., Gyótapuszta 1992. Hosszúvíz 1992., Nagybajom 1992., Tótújfalu 1994., Töreki 1994.

\section{Farkaspókok - Lycosidae}

Alopecosa cuneata (Clerck, 1757) - Barcs 1985., Böhönye 1992., Nagybajom 1992., Potony 1993.

Alopecosa cursor (Hahn, 1831) - Barcs 1980.

Alopecosa pulverulenta (Clerck, 1757) Barcs 1975., Nagybajom 1992.

Alopecosa solitaria (Herman, 1879) Balatonboglár 1897.

Alopecosa sulzeri (Pavesi, 1873) - Barcs 1975., Nagybajom 1992.

Alopecosa trabalis (Clerck, 1757) - Nagybajom 1992. 
Arctosa figurata (Simon, 1876) - Nagybajom 1992. 1980

Arctosa leopardus (Sundevall, 1833) - Barcs

Arctosa lutetiana (Simon, 1876) - Barcs 1975., Bolhó 1993., Töreki 1994.

Arctosa maculata Hahn, 1822 - Órtilos 1995.

Arctosa perita (Latreille, 1799) Balatonlelle 1897.

Aulonia albimana (Walckenaer, 1805) Barcs 1975., Bolhó 1993., Nagybajom 1992. Töreki 1994.

Hogna radiata (Latreille, 1819) - Barcs 1980.

Hygrolycosa rubrofasciata (Ohlert, 1865) Barcs 1985., Bolhó 1993. 1897

Lycosa vultuosa C.L. Koch, 1838 - Szántód

Pardosa agrestis (Westring, 1862) - Hoszszúvíz 1992.

Pardosa alacris (C.L. Koch, 1833) - Barcs 1975., Bélavár 1995., Bolhó 1993., Gyékényes 1993., Órtilos 1993.

Pardosa amentata (Clerck, 1757) - Babócsa 1997., Bolhó 1993., Nagybajom 1992., Órtilos 1993., 1995., 1996.

Pardosa bifasciata (C.L. Koch, 1834) Barcs 1975., Nagybajom 1992.

Pardosa lugubris (Walckenaer, 1802) Barcs 1980., Bélavár 1995., Bolhó 1993. Böhönye 1992., Gyótapuszta 1992., Hosszúvíz 1992., Nagybajom 1992., Örtilos 1993., Töreki 1994. 1897.

Pardosa nebulosa (Thorell, 1872) — Szántód

Pardosa palustris (Linnaeus, 1758) Hosszúvíz 1992.

Pardosa proxima (C.L. Koch, 1847) — Zákány 1897.

Pardosa pullata (Clerck, 1757) - Nagybajom 1992., Zákány 1897.

Pardosa riparia (C.L. Koch, 1833) - Nagybajom 1992.

Pirata hygrophilus Thorell, 1872 - Barcs 1975., Böhönye 1992., Hosszúvíz 1992., Nagybajom 1992., Órtilos 1993. 1996.

Pirata latitans (Blackwall, 1841) - Örtilos

Pirata piraticus (Clerck, 1757) - Bélavár 1996., Ôrtilos 1995., 1996., Töreki 1994.

Pirata uliginosus (Thorell, 1856) - Bolhó 1993., Böhönye 1992.

Trochosa ruricola (Degeer, 1778) - Bolhó 1993., Órtilos 1993., Töreki 1994.

Trochosa spinipalpis (F.O.P.-Cambridge, 1895) - Bélavár 1995., Böhönye 1992., Hosz- szúvíz 1992., Nagybajom 1992.

Trochosa terricola Thorell, 1856 - Barcs 1975., Bélavár 1995., Bolhó 1993., Gyótapuszta 1992., Hosszúvíz 1992., Nagybajom 1992.

Xerolycosa miniata (C.L. Koch, 1834) Hosszúvíz 1992.

Xerolycosa nemoralis (Westring, 1861) Barcs 1980.

\section{Csodáspókok - Pisauridae}

Dolomedes fimbriatus (Clerck, 1757) - Barcs 1985., Böhönye 1992., Hosszúvíz 1992., Nagybajom 1992., Órtilos 1996., 1997. Tótúifalu 1994.

Dolomedes plantarius (Clerck, 1757) - Vízvár 1999.

Pisaura mirabilis (Clerck, 1757) - Barcs 1975., Böhönye 1992., Gyékényes 1994. Gyótapuszta 1992., Hosszúvíz 1992., Nagybajom 1992., Órtilos 1992., 1996., 1997. Porrogszentkirály 1994., Szántód $1897 .$, Tótújfalu 1994., Töreki 1994.

\section{Hiúzpókok - Oxyopidae}

Oxyopes lineatus Latreille, 1806 - Darány 1992., 1994., 1997., Nagybajom 1992., Tótújfalu 1994.

Oxyopes ramosus (Panzer, 1804) - Darány 1997., Hosszúvíz 1992., Nagybajom 1992.

\section{Zugpókok - Agelenidae}

Agelena gracilens C.L. Koch, 1841 - Barcs 1985., Hosszúvíz 1992., Nagybajom 1992. Örtilos 1992., 1994., 1995., Porrogszentkirály 1994., Tótújfalu 1994., Töreki 1994.

Agelena labyrinthica (Clerck, 1757) - Gyékényes 1994., Potony 1994.

Tegenaria campestris C.L. Koch, 1834 Bélavár 1995., Bolhó 1993., Böhönye 1992. 1997

Tegenaria silvestris L. Koch, 1872 - Órtilos

Textrix denticulata (Olivier, 1789) Balatonföldvár 1897.

\section{Tárnapókok - Cybaeidae}

Cybaeus angustiarum L. Koch, 1868 - Örtilos 1993.

\section{Parány-zugpókok - Hahniidae}

Hahnia ononidum Simon, İ875 - Barcs 1980., Örtilos 1996.

Hahnia pusilla C.L. Koch, 1841 - Barcs 1980., Böhönye 1992., Hosszúvíz 1992. 


\section{Hamvaspókok - Dictynidae}

Argenna patula (Simon, 1874) - Zákány 1897.

Dictyna arundinacea (Linnaeus, 1758) Babócsa 1997., Töreki 1994. 1994.

Dictyna latens (Fabricius, 1775) - Töreki

Dictyna uncinata Thorell, 1856 - Hosszúvíz 1992., Ôrtilos 1995., 1996., 1997., Szántód 1897., Töreki 1994.

Lathys humilis (Blackwall, 1855) - Darány 1997., Gyékényes 1994., Tótújfalu 1994.

Lathys puta (O.P.-Cambridge, 1863) Barcs 1980

Nigma flavescens (Walckenaer, 1830) Böhönye 1992., Hosszúvíz 1992., Nagybajom 1992., Szántód 1897.

\section{Eretnekpókok - Amaurobidae} 1992.

Coelotes inermis (L. Koch, 1855) - Böhönye

\section{Mészpókok - Titanoecidae}

Titanoeca quadriguttata (Hahn, 1833) Tótújfalu 1994.

Titanoeca schineri (L. Koch, 1872) - Barcs 1975., Töreki 1994.

\section{Jegyespókok - Anyphaenidae}

Anyphaena accentuata (Walckenaer, 1802) Böhönye 1992., Darány 1997., Gyékényes 1994., Hosszúvíz 1992., Nagybajom 1992., Örtilos 1992., 1996., 1997., Tótúffalu 1994., Töreki 1994.

\section{Avarpókok - Liocranidae}

Agraecina striata (Kulczynski, 1882) Barcs 1975., Böhönye 1992., Gyótapuszta 1992.

Agroeca brunnea (Blackwall, 1833) - Barcs

1975., Bélavár 1995., Bolhó 1993., Böhönye 1992., Hosszúvíz 1992., Nagybajom 1992., Potony 1993., Töreki 1994.

Agroeca cuprea Menge, 1873 - Barcs 1975. Apostenus fuscus Westring, 1851 - Böhönye 1992.

Phrurolithus festivus (C.L. Koch, 1835) Balatonlelle 1897., Barcs 1975., Töreki 1994.

Phrurolithus minimus C.L. Koch, 1839 Barcs 1975., Hosszúvíz 1992.

Phrurolithus pullatus Kulczynski, 1897 Barcs 1975. 1975

Phrurolithus szilyi (Herman, 1879) - Barcs

Scotina celans (Blackwall, 1841) - Barcs 1980.

\section{Kalitpókok - Clubionidae}

Cheiracanthium erraticum (Walckenaer, 1802) - Nagybajom 1992.

Cheiracanthium punctorium (Villers, 1789) Hosszúvíz 1992., Nagybajom 1992., Porrogszentkirály 1994., Tótújfalu 1994.

Cheiracanthium virescens (Sundevall, 1833) Nagybajom 1992.

Clubiona alpicola Kulczynski, 1881 Tótjújfalu 1994. 1996.

Clubiona brevipes Blackwall, 1841 - Órtilos

Clubiona caerulescens L. Koch, 1867 Nagybajom 1992.

Clubiona comta C.L. Koch, 1839 - Barcs 1985., Böhönye 1992., Darány 1997. 1992.

Clubiona germanica Thorell, 1870 - Órtilos

Clubiona lutescens Westring, 1851 Böhönye 1992., Ốrtilos 1995., Zákány 1897.

Clubiona pallidula (Clerck, 1757) Gyótapuszta 1992., Nagybajom 1992., Órtilos 1993., 1995., 1996., 1997.

Clubiona phragmitis C.L. Koch, 1843 Barcs 1985., Órtilos 1993., 1997.

Clubiona pseudoneglecta Wunderlich, 1994 Nagybajom 1992.

Clubiona stagnatilis Kulczynski, 1897 Barcs 1985.

Clubiona subtilis L. Koch, 1867 - Barcs 1985. Clubiona terrestris Westring, 1851 - Órtilos 1993., 1997.

Clubiona trivialis C.L. Koch, 1843 Tótújfalu 1994.

\section{Búvópókok - Zodariidae}

Zodarion germanicum (C.L. Koch, 1837) Barcs 1975., Gyótapuszta 1992., Töreki 1994.

\section{Kövipókok - Gnaphosidae}

Aphantaulax seminigra Simon, 1878 Balatonlelle 1897., Darány 1992., 1997.

Berlandina cinerea (Menge, 1872) - Barcs 1980., Nagybajom 1992.

Drassodes lapidosus (Walckenaer, 1802) Barcs 1980., Nagybajom 1992., Szántód 1897.

Drassodes pubescens (Thorell, 1856) Böhönye 1992., Gyótapuszta 1992., Nagybajom 1992., Töreki 1994.

Drassyllus lutetianus (L. Koch, 1866) Balatonlelle 1897.

Drassyllus praeficus (L. Koch, 1866) - Barcs 1975., Böhönye 1992., Nagybajom 1992., Töreki 1994. 
Drassyllus pumilus (C.L. Koch, 1839) Gyótapuszta 1992.

Drassyllus pusillus (C.L. Koch, 1833) - Töreki 1994.

Drassyllus villicus (Thorell, 1875) - Barcs 1980., Gyótapuszta 1992., Töreki 1994.

Gnaphosa modestior Kulczynski, 1897 Barcs 1985., Nagybajom 1992.

Gnaphosa opaca Herman, 1879 Balatonboglár 1897.

Haplodrassus moderatus (Kulczynski, 1897) Balatonlelle 1897.

Haplodrassus signifer (C.L. Koch, 1839) Barcs 1980., Töreki 1994.

Haplodrassus silvestris (Blackwall, 1833) Barcs 1980., Böhönye 1992., Gyótapuszta 1992., Nagybajom 1992., Töreki 1994.

Micaria fulgens (Walckenaer, 1802) - Töreki 1994.

Micaria pulicaria (Sundevall, 1832) Balatonlelle 1897., Töreki 1994.

Micaria romana L. Koch, 1866 - Töreki 1994.

Micaria subopaca Westring, 1862 - Szántód 1897.

Poecilochroa conspicua (L. Koch, 1866) Nagybajom 1992.

Trachyzelotes pedestris (C.L. Koch, 1837) Barcs 1985., Böhönye 1992, Nagybajom 1992., Töreki 1994.

Scotophaeus quadripunctatus (Linnaeus, 1758) - Szántód 1897.

Zelotes apricorum (L. Koch, 1876) - Töreki 1994.

Zelotes aurantiacus Miller 1967- Töreki 1994.

Zelotes electus (C.L. Koch, 1839) - Barcs 1975., Nagybajom 1992., Töreki 1994.

Zelotes erebeus (Thorell, 1870) - Barcs 1975., Gyótapuszta 1992.

Zelotes hermanni (Chyzer, 1878) - Barcs 1975., Töreki 1994.

Zelotes latreillei (Simon, 1878) Balatonlelle 1897., Barcs 1975., Nagybajom 1992., Töreki 1994.

Zelotes longipes (L. Koch, 1866) - Barcs 1975., Töreki 1994.

Zelotes petrensis (C.L. Koch, 1839) - Nagybajom 1992., Töreki 1994.

Zelotes pygmaeus Miller, 1943 - Töreki 1994.

Zelotes subterraneus (C.L. Koch, 1833) Nagybajom 1992., Töreki 1994.

\section{Párducpókok - Zoridae}

Zora nemoralis (Blackwall, 1861) -

Böhönye 1992, Hosszúviz 1992, Nagybajom 1992.

Zora silvestris Kulczynski, 1897 - Barcs 1975.

Zora spinimana (Sundevall, 1833) - Barcs 1975., Böhönye 1992., Hosszúvíz 1992., Órtilos 1996., 1997.

\section{Vadászpókok - Heteropodidae}

Micrommata virescens (Clerck, 1757) - Örti$\operatorname{los} 1992$.

\section{Futópókok - Philodromidae}

Philodromus albidus Kulczynski, 1911 Bélavár 1994., Töreki 1994.

Philodromus aureolus (Clerck, 1757) sensu lato - Böhönye 1992., Gyótapuszta 1992., Hosszúvíz 1992., Nagybajom 1992.

Philodromus cespitum (Walckenaer, 1802) Szulok 1897., Zákány 1897.

Philodromus collinus C.L. Koch, 1835 Darány 1997.

Philodromus dispar Walckenaer, 1826 Böhönye 1992., Gyótapuszta 1992., Hosszúvíz 1992., Nagybajom 1992., Órtilos 1996., 1997.

Philodromus rufus Walckenaer, 1826 Hosszúvíz 1992.

Thanatus arenarius Thorell, 1872 - Szántód 1897.

Thanatus formicinus (Clerck, 1757) - Barcs 1975., Nagybajom 1992., Töreki 1994.

Thanatus sabulosus (Menge, 1875) - Barcs 1975.

Thanatus striatus C.L. Koch, 1845 Balatonlelle 1897

Tibellus macellus Simon, 1875 - Szulok 1897.

Tibellus maritimus (Menge, 1875) - Órtilos 1995., 1996., Töreki 1994.

Tibellus oblongus (Walckenaer, 1802) Böhönye 1992., Hosszúvíz 1992., Nagybajom 1992., Töreki 1994.

\section{Karolópókok - Thomisidae}

Diaea dorsata (Fabricius, 1777) - Böhönye 1992., Hosszúvíz 1992., Órtilos 1992.

Heriaeus graminicola (Doleschall, 1852) Bélavár 1996.

Heriaeus melloteei Simon, 1886 - Hosszúvíz 1992., Nagybajom 1992.

Misumena vatia (Clerck, 1757) - Böhönye 1992., Gyékényes 1995., Hosszúvíz 1992., Nagybajom 1992., Órtilos 1994., Szulok 1897. Misumenops tricuspidatus (Fabricius, 1775) Bélavár 1994., Böhönye 1992., Hosszúvíz 
1992., Nagybajom 1992., Örtilos 1992., 1996., Szántód 1897., Szulok 1897., Tótúifalu 1994., Töreki 1994.

Ozyptila atomaria (Panzer, 1801) - Barcs 1975., Nagybajom 1992., Órtilos 1996. 1985

Ozyptila brevipes (Hahn, 1826) - Barcs

Ozyptila claveata (Walckenaer, 1837) Barcs 1975., Töreki 1994.

Ozyptila praticola (C.L. Koch, 1837) Bolhó 1993., Böhönye 1992., Hosszúvíz 1992., Töreki 1994., Zákány 1897.

Ozyptila simplex (O.P.-Cambridge, 1862) Mailáthpuszta 1994.

Ozyptila trux (Blackwall, 1846) - Barcs 1985., Hosszúvíz 1992.

Runcinia grammica (C.L. Koch, 1837) Órtilos 1996.

Synaema globosum (Fabricius, 1775) Böhönye 1992., Darány 1994., Hoszúvíz 1992., Nagybajom 1992., Órtilos 1992.

Thomisus onustus Walckenaer, 1806 Gyótapuszta 1992., Hosszúviz 1992,, Nagybajom 1992., Szulok 1897.

Tmarus piger (Walckenaer, 1802) - Barcs 1985., Böhönye 1992., Gyótapuszta 1992., Hosszúvíz 1992., Nagybajom 1992., Örtilos 1992., 1996., 1997., Potony 1994.

Xysticus bifasciatus C.L. Koch, 1837 Nagybajom 1992.

Xysticus cristatus (Clerck, 1857) - Nagybajom 1992.

Xysticus erraticus (Blackwall, 1834) Nagybajom 1992., Töreki 1994. 1996.

Xysticus kempeleni Thorell, 1872 - Órtilos

Xysticus kochi Thorell, 1872 - Barcs 1980., Darány 1997., Nagybajom 1992., Órtilos 1996., Töreki 1994.

Xysticus lineatus (Westring, 1851) - Nagybajom 1992.

Xysticus luctator L. Koch, 1870 - Barcs 1980., Bolhó 1993., Potony 1993.

Xysticus luctuosus (Blackwall, 1836) Potony 1993.

Xysticus ninnii Thorell, 1872 - Barcs 1980., Bélavár 1996.

Xysticus sabulosus (Hahn, 1832) - Nagybajom 1992.

Xysticus striatipes L. Koch, 1870 - Darány 1992., Nagybajom 1992.

Xysticus ulmi (Hahn, 1831) - Böhönye 1992., Gyótapuszta 1992., Hosszúvíz 1992., Nagybajom 1992., Órtilos 1996., 1997.
Ugrópókok - Salticidae

Aelurillus v-insignitus (Clerck, 1757) -

Balatonlelle 1897.

Ballus chalybeius (Walckenaer, 1802) Bélavár 1994., Böhönye 1992., Gyótapuszta 1992., Hosszúvíz 1992., Nagybajom 1992., Órtilos 1992., 1995., 1996., 1997., Töreki 1994.

Bianor aurocinctus (Ohlert, 1865) Balatonlelle 1897., Bélavár 1996., Hosszúvíz 1992.

Carrhotus xanthogramma (Latreille, 1819) Barcs 1985.

Dendryphantes rudis (Sundevall, 1832) Darány 1997., Nagybajom 1992., Tótújfalu 1994.

Euophrys erratica (Walckenaer, 1826) Barcs 1980., Töreki 1994.

Euophrys frontalis (Walckenaer, 1802) Barcs 1975., Nagybajom 1992., Töreki 1994.

Evarcha arcuata (Clerck, 1757) - Bélavár 1996., Darány 1997., Gyékényes 1994., Gyótapuszta 1992., Hosszúvíz 1992., Nagybajom 1992., Örtilos 1997., Töreki 1994.

Evarcha falcata (Clerck, 1757) - Bolhó 1993., Gyótapuszta 1992., Nagybajom 1992., Szulok 1897., Tótújfalu 1994.

Evarcha laetabunda (C.L. Koch, 1846) Barcs 1980.

Heliophanus auratus C.L. Koch, 1835 Bélavár 1996., Hosszúvíz 1992., Nagybajom 1992., Órtilos 1995., 1996.

Heliophanus cupreus (Walckenaer, 1802) -

Darány 1997., Szulok 1897.

Macaroeris nidicolens (Walckenaer, 1802) Gyékényes 1994., Órtilos 1996., 1997.

Marpissa canestrinii Ninni, 1868 - Barcs 1985., Órtilos 1995., 1996.

Marpissa muscosa (Clerck, 1757) Böhönye 1992., OÓrtilos 1996., 1997., Tótújfalu 1994.

Marpissa nivoyi (Lucas, 1846) - Barcs 1975.

Marpissa radiata (Grube, 1859) - Nagybajom 1992.

Myrmarachne formicaria (Degeer, 1778) Örtilos 1995., Töreki 1994.

Neon reticulatus (Blackwall, 1853) - Barcs 1975.

Pellenes tripunctatus (Walckenaer, 1802) Nagybajom 1992.

Philaeus chrysops (Poda, 1761) - Darány 1994., 1997., Nagybajom 1992.

Phintella castriesiana (Grube, 1861) - Órtilos 1995., 1996. 
Phlegra fasciata (Hahn, 1826) - Nagybajom 1992.

Phlegra festiva (C.L. Koch, 1834) - Nagybajom 1992. 1995.

Salticus cingulatus (Panzer, 1797) — Órtilos

Salticus zebraneus (C.L. Koch, 1837) Böhönye 1992., Darány 1997., Gyékényes 1994., Örtilos 1996.

Sitticus distinguendus (Simon, 1868) Balatonlelle 1897.
Sitticus floricola (C.L. Koch, 1837) - Örtilos 1995., Szántód 1897.

Sitticus pubescens (Fabricius, 1775) Balatonboglár 1897.

Sitticus saltator (O. P.-Cambridge in Simon, 1868) - Balatonlelle 1897.

Sitticus zimmermanni (Simon, 1877) Balatonlelle 1897.

Talavera petrensis (C.L. Koch, 1837) - Töreki 1994.

\section{I. táblázat: Somogy megye területéról kimutatott pókcsaládok és fajszámaik}

\begin{tabular}{|c|c|}
\hline Család & Fajszám \\
\hline Torzpókfélék - Atypidae & 2 \\
\hline Aknászpókfélék - Nemesiidae & 1 \\
\hline Álkaszáspókok - Pholcidae & l \\
\hline Darócpókok - Segestridae & 2 \\
\hline Folytópókok - Dysderidae & 4 \\
\hline Bütykös pókok - Mimetidae & 3 \\
\hline Derespókok - Uloboridae & 2 \\
\hline Törpepókok - Theridiidae & 25 \\
\hline Törpe-keresztespókok - Theridiosomatidae & l \\
\hline Mysmenidae - Paránypókok & 1 \\
\hline Vitorláspókok - Linyphiidae & 61 \\
\hline Állaspókok - Tetragnathidae & I l \\
\hline Keresztespókok - Araneidae & 29 \\
\hline Farkaspókok - Lycosidae & 34 \\
\hline Csodás pókok - Pisauridae & 3 \\
\hline Hiúzpókok - Oxyopidae & 2 \\
\hline Zugpókok - Agelenidae & 5 \\
\hline Tárnapókok - Cybaeidae & I \\
\hline Parány-zugpókok - Hahniidae & 2 \\
\hline Hamvaspókok - Dictynidae & 7 \\
\hline Eretnckpókok - Amaurobidae & $\mathrm{l}$ \\
\hline Mészpókok-Titanoecidae & 2 \\
\hline Jegyespókok - Anyphaenidae & $\mathrm{I}$ \\
\hline Avarpókok - Liocranidae & 9 \\
\hline Kalitpókok - Clubionidae & 16 \\
\hline Búvópókok - Zodariidae & 1 \\
\hline Kövipókok - Gnaphosidae & 31 \\
\hline Párducpókok - Zoridae & 3 \\
\hline Vadászpókok - Heteropodidae & 1 \\
\hline Futópókok - Philodromidae & 13 \\
\hline Karolópókok - Thomisidae & 27 \\
\hline Ugrópókok - Salticidae & 32 \\
\hline Összesen: & 334 \\
\hline
\end{tabular}




\section{Köszönetnyilvánítás}

Köszönetemet fejezem ki mindazoknak, akik segítséget nyújtottak jelen közlemény elkészítéséhez. Külön köszönet illeti Dr. Ábrahám Leventét és Dr. Uherkovich Ákost, akik révén lehetőségem nyílt arra, hogy Somogy megye egyes területeinek faunakutatásába bekapcsolódhassam. Köszönet a kutatási feltételek biztosításáért. Köszönöm az általuk vezetett múzeumi kollektíváknak (Somogy Megyei Múzeum, Janus Pannonius Múzeum) a kilencvenes években végzett gyứjtőmunkákat. Kiemelt köszönet illeti volt mesteremet Dr. Loksa Imrét, aki a 1975 és 1985 között számos alkalommal végzett alapos gyüjtéseket a területen. Az általa gyưijtött anyagokat Dr. Loksa Imréné bocsátotta a rendelkezésemre. Segítségét ezúton is köszönöm. Végezetül, de nem utolsósorban köszönetemet fejezem ki családtagjaimnak, akik több ízben aktívan részt vettek a gyújtőútjaimon.

A közlemény a Bolyai János Kutatási Ösztöndíj támogatásával készült.

\section{Irodalom}

ChYZER, K. \& KULCZYNSKI, L. 1891: Araneae Hungariae. Tomus I: Salticoidae, Oxyopoidae, Lycosoidae, Heteropodoidae, Misumenoidae, Euetrioidae, Tetragnathoidae, Uloboroidae, Pholcoidae, Scytodoidae, Urocteoidae, Eresoidae, Dictynoidae. - Academie Scientiarum Hungaricae, Budapest.

CHYZER, K. \& KULCZYNSKI, L. 1894: Araneae Hungariae. Tomus II, pars prior: Theridioidae. Academie Scientiarum Hungaricae, Budapest.

CHYZER, K. \& KUlCZYNSKI, L. 1897: Araneae Hungariae. Tomus II. pars posterior: Zodarioidae, Agalenoidae, Drassoidae, Zoropseoidae, Dysderoidae, Filistatoidae, Calommatoidae, Theraphosoidae. Academie Scientiarum Hungaricae, Budapest.

Farkas, J., Szathmár, K. \& Strenner, A. 1998: Ecofaunistical investigations of Collembola, Araneae and Coleoptera in mosaic-like habitats in the Cinege Valley, Hungary. Opusc. Zool. Budapest, 31: 49-61.

KolosvÁRY, G., 1935: Neue Beiträge zur Biologie der Tierwelt der ungarländischen Junipereten. Folia Zoologica et Hydrobiologica 7: 203-216.

SAMU, F, SZINETÁR, Cs. 1999: Bibliographic check list of the Hungarian spider fauna. -Bull. Br. arachnol. Soc. II (5): 161-184.

SzINETÁr, Cs. 1992: A Boronka-melléki Tájvédelmi Körzet pókfaunája. - Dunántúli Dolgozatok Természettudományi Sorozat 7: 331-345.

SzINETÁr, Cs. 1998: A Dráva mente pókfauna (Araneae) kutatásának faunisztikai eredményei. A Dráva mente állatvilága, II. Dunántúli Dolgozatok Természettudományi Sorozat 9: 97-1 10. 


\title{
Spider fauna of Somogy county (Aranea)
}

\section{CSABA SZINETÁR}

The first data regarding the spider fauna of Somogy county can be found in the work of CHYZER and KULCZYNSKI (1891, 1894, 1897). Owing to the contribution of several enthusiastic collectors (Lajos Bíró, József Jablonovszky, Géza Horváth, Adolf Lendl, János Pável) we have data from the southern side of Lake Balaton (Balatonföldvár, Balatonszentgyörgy, Boglár, Fonyód, Lelle, Szántód) as well as from Szulok and Zákány. The fauna checklist includes the above data together with the settlement's name as well as the publication date of Araneae Hungariae II (1897). Regarding the former investigations, the publications of Gábor Kolosváry regarding the Hungarian juniper fauna have to be mentioned. The author referred several times to the Juniper area at Darány, where the spiders living on junipers together with other animal species have also been studied (KOLOSVÁRY 1935). In the fauna researches exploring the Barcsi Borókás Landscape Protection Area, Imre Loksa had a significant role, collecting - among other animal species - the spiders as well. The publication of his material collected by him and partly worked up appeared in the 2nd Volume of the Danube-Dráva National Park Research (SzINETÁR 1998). The author of this publication joined the exploration of the county's spider fauna on the invitation of the Somogy County Museum in the early nineties. The exploration performed in early nineties of the Boronka-melléki Landscape Protection Area revealed the typical habitats in the central areas of the county. The well-conserved acidic sandy grasses and alder marsh-woods were especially valuable (SZINETÁr 1992). Among the most significant habitats of the Boronka Landscape-Protection Area, Böhönye (Mernyei-Woods), Nagybajom (Farakodó), Gyótapuszta (Gyótai-Woods), and Hosszúvíz have to be mentioned. In the second half of the nineties researches were carried out within the frames of the Danube-Dráva National Park Research on areas of the National Park belonging to Somogy county, such as: Zákány-Órtilos Hills, Barcsi Borókás Landscape-Protection Area as well as in the areas of Bélavár, Bolhó, Babócsa, Pótony and Tótújfalu (Szinetár 1998). Farkas et al. examined the spiders (among other animals) during 1993-94 in Cinege Creek valley (Töreki, south of Siófok) (FARKAS et al. 1998). As a result of these investigations, 334 spider species were identified on the area of Somogy county. This means $46 \%$ of the Hungarian spider fauna (SAMU and SZINETÁr 1999). A significant part of the county can be still deemed as unexplored. In the followings, the Zselic and the Somogy part of Lake Balaton shoreline could be especially interesting. Hopefully, the present publication will help to draw the attention to the natural values of Somogy county and to encourage the future researches.

\author{
Dr. Csaba Szinetár \\ Department of Zoology Berzsenyi College \\ H-9701 Szombathely \\ Károlyi Gáspár tér 4. \\ HUNGARY \\ E-mail:szcsaba@fs2.bdtf.hu
}

